\title{
Effect of amino acid addition on the micelle formation of surface active ionic liquid, 1-tetradecyl-3-methylimidazolium bromide in aqueous solution
}

\author{
Mabel Rojas, ${ }^{(\mathrm{a})}$ Zsombor Miskolczy, ${ }^{(\mathrm{b})}$ László Biczók $^{(\mathrm{b})}$ and Paulina Pavez*(a)
}

(a) Facultad de Química, Pontificia Universidad Católica de Chile, Casilla 306, Santiago 6094411, Chile

(b) Institute of Materials and Environmental Chemistry, Research Centre for Natural Sciences, Hungarian Academy of Sciences, P.O. Box 286, 1519 Budapest, Hungary

\begin{abstract}
Author Information
*Corresponding authors. Tel.: +56-02-23541743; fax: +56-02-26864744; e-mail: ppavezg@uc.cl

Present address: Facultad de Química, Pontificia Universidad Católica de Chile, Av. Vicuña Mackenna 4860, Santiago 6094411, Chile.
\end{abstract}




\begin{abstract}
.
The effect of three amino acids on the self-organization of surface active ionic liquid, 1tetradecyl-3-methyl imidazolium bromide, $\left[\mathrm{C}_{14} \mathrm{mim}^{+}\right]\left[\mathrm{Br}^{-}\right]$was studied in neutral and basic aqueous solution. The critical micelle concentrations $(\mathrm{cmc})$ were determined by surface tension, conductivity, steady-state fluorescence measurements and isothermal titration calorimetry (ITC). Thermodynamics parameters of micellization $\left(\Delta \mathrm{G}^{0}\right.$ mic, $\Delta \mathrm{H}^{0}{ }_{\text {mic }}$ and $\left.\Delta \mathrm{S}^{0}{ }_{\text {mic }}\right)$ were measured by ITC.

The cmc values decrease in presence of all amino acids used in this study. The most substantial effect was observed in presence of L-tryptophan at $\mathrm{pH} 12$, due to the electrostatic and $\pi-\pi$ interactions with the imidazolium headgroup of the surfactant. Always entropy-driven micellization occurred. Both the enthalpy and entropy changes upon association to micelles increased when the $\mathrm{pH}$ was enhanced from 7 to 12 .

${ }^{1} \mathrm{H}$ NMR measurements demonstrated that among the used amino acids L-tryptophan interacts most strongly with the headgroup of surfactant cation.
\end{abstract}




\section{Introduction}

Ionic liquids (ILs) have received much attention in the last decades due to their unique physicochemical characteristics, such as negligible vapor pressures, non-flammability, and easy recyclability, among others. ${ }^{1}$ Due to their advantageous properties, ILs has been used as solvents in many fields including preparation of novel nanomaterials, organic synthesis, homogeneous catalysis, and electrochemistry. ${ }^{2,3}$ In addition, the homologues containing a long hydrophobic alkyl chain can self-assemble to various types of aggregates in aqueous solutions such as micelles, ${ }^{4-6}$ vesicles, ${ }^{7}$ lyotropic liquid crystals (LLCs) ${ }^{8-10}$ and gels. ${ }^{11}$ These ILs, generally named as surface active ionic liquids (SAILs), have been extensively studied. It has been demonstrated that the length of alkyl chain, type of head of group and the nature of counterions affects the self-aggregation, ${ }^{12-14}$ leading to modification in cmc, size, shape, and aggregation number $\left(N_{\text {agg }}\right)$; among others. ${ }^{14}$

The most frequently studied SAILs are 1-alkyl-3-methylimidazolium $\left(\left[\mathrm{C}_{\mathrm{n}} \mathrm{mim}^{+}\right]\right)$cations containing halide $\left(\mathrm{Br}^{-} ; \mathrm{Cl}^{-}\right)$or fluorinated $\left[\mathrm{BF}_{4}^{-}\right]$; $\left[\mathrm{PF}_{6}^{-}\right]$; bis(trifluoromethylsulfonyl)imide $\left(\left[\mathrm{NTf}_{2}{ }^{-}\right]\right)$anions. ${ }^{15-17}$ The alkyl chain length of $\left[\mathrm{C}_{\mathrm{nmim}}{ }^{+}\right]$and the nature of the counterions affect both the micellization properties and micelle shape. ${ }^{15,17,18}$ For example, only $\left[\mathrm{C}_{\mathrm{n}} \mathrm{mim}^{+}\right] \mathrm{Cl}^{-}$with $n>8$ form aggregates in solution and when $\mathrm{Cl}^{-}$was replaced by $\left[\mathrm{NTf}_{2}^{-}\right]$ or $\left[\mathrm{PF}_{6}{ }^{-}\right]$anions, no micelle formation was detected. ${ }^{15}$ Moreover, other types of SAILs with varied ring type of the cations, such as alkylpyridinium $\left(\left[\mathrm{C}_{\mathrm{n}} \mathrm{Py}^{+}\right]\right)$, alkylmethylpyrrolidinium $\quad\left(\left[\mathrm{C}_{\mathrm{n}} \mathrm{mPyrr}^{+}\right]\right), \quad$ alkylmethylpiperidinium $\quad\left(\left[\mathrm{C}_{\mathrm{n}} \mathrm{mpip}{ }^{+}\right]\right)$, morpholinium $\left(\left[\mathrm{C}_{\mathrm{n}} \mathrm{Morph}^{+}\right]\right)$, have been reported. ${ }^{19-22}$ Wang et al. found that the hydrophobicity and steric hindrance of cations had very weak effects on the morphology, but played an important role in the control of the size of aggregates. ${ }^{19}$ In addition, other parameters such as temperature and the presence of inorganic or organic additive exerted a significant effect on the self-aggregation behavior of a number of surfactants. ${ }^{23-26}$ Structural and thermodynamic studies have been performed on surfactant-water systems including the effect of additives on micellization. ${ }^{24,27}$ The addition of salicylate ions to aqueous solution of the cationic surfactant alkyltrimethylammonium type $\left[\mathrm{RTA}^{+}\right]$lead to considerable changes in the properties of self-aggregation. These results have been explained by the peculiar manner of salicylate binding to the micelles. Due to its amphiphilic character, the 
salicylate inserts its benzene ring into the hydrophobic part of the micelle. ${ }^{28}$ In contrast, addition of glutamine, histidine and methionine barely influenced the cmc of sodium dodecyl benzene sulfonate and dodecyltrimethylammonium bromide. ${ }^{24}$

Previous studies revealed that surfactants are usually toxic which hinders their applications in many fields. ${ }^{29}$ Therefore, the syntheses and study of more eco-friendly surfactants composed of biocompatible constituents represents an important challenge.

Recent studies on the counterion effect on the physicochemical characteristics of a new enviromental friendly surfactant, ethane-1,2-diyl bis(N,N-dimethyl-N-tetradecylammoniumacetoxy) dichloride found that the rise of anthranilate or tosylate concentration brought about substantial reduction in cmc values and surfactant headgroup area which was accompanied with a significant growth of aggregation number because of the incorporation of these organic anion into the palisade layer of micelles. ${ }^{23}$ The only electrostatically bound inorganic anions exerted smaller effect.

The main goal of the present work was to reveal how the presence of L-alanine (L-Ala), Lphenylalanine (L-Phe) and L-tryptophan (L-Trp) amino acids modified the micellization properties of 1-tetradecyl-3-methylimidazolium bromide $\left[\mathrm{C}_{14} \mathrm{mim}^{+}\right]\left[\mathrm{Br}^{-}\right]$in aqueous solution (Figure 1). Experiments were carried out at $\mathrm{pH} 7$ and $\mathrm{pH}$ 12, where zwitterionic and anionic forms of amino acids dominate, respectively. Conductivity, surface tension (ST), NMR, and steady-state fluorescence spectroscopic measurements combined with isothermal titration calorimetry (ITC) provide a comprehensive view on the interaction of amino acids with $\left[\mathrm{C}_{14} \mathrm{mim}^{+}\right]\left[\mathrm{Br}^{-}\right]$micelles. 

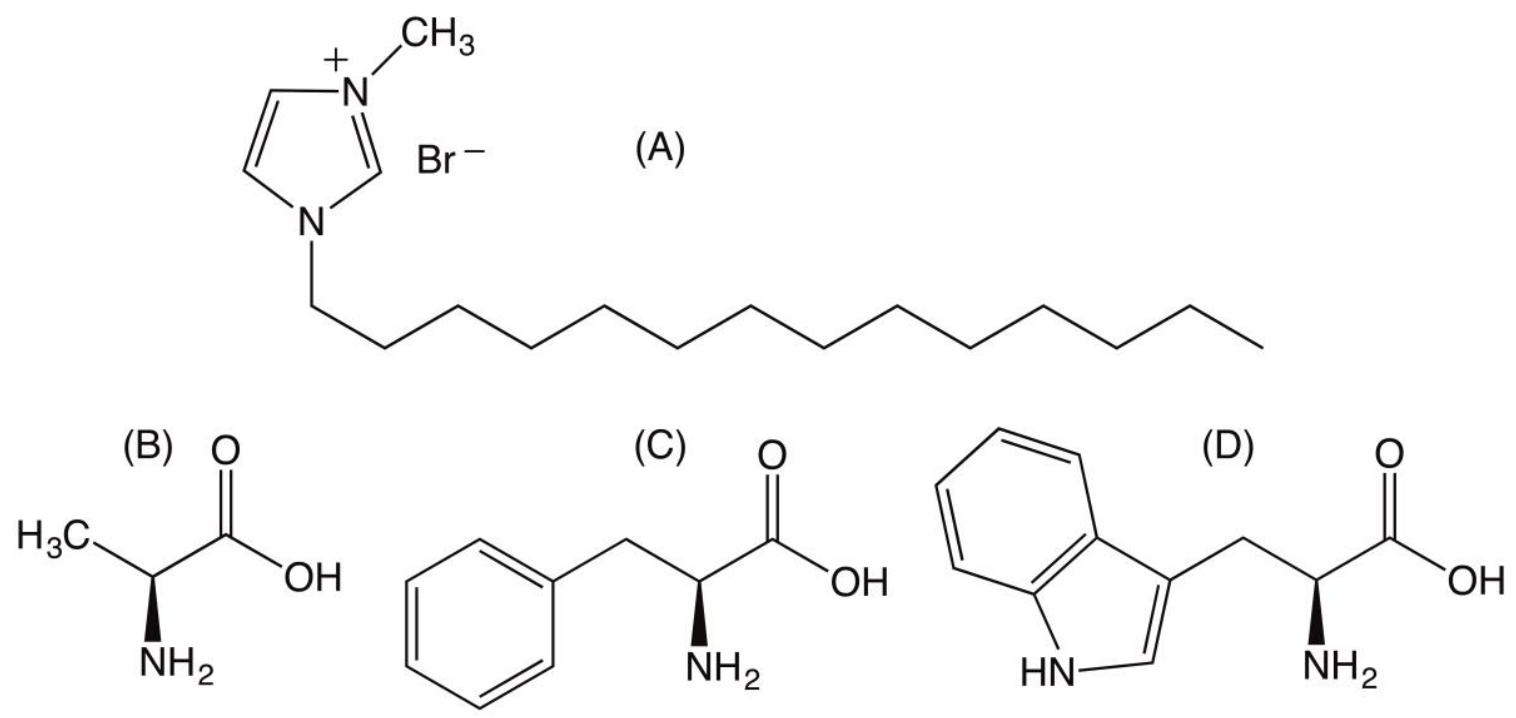

Figure 1. Structure of (A) 1-tetradecyl-3-methylimidazolium bromide $\left(\left[\mathrm{C}_{14} \mathrm{mim}^{+}\right][\mathrm{Br}-]\right)$; (B) L-alanine (L-Ala); (C) L-phenylalanine (L-Phe) and (D) L-tryptophan (L-Trp).

\section{Experimental Section}

\subsection{Materials.}

Commercially available reagents and solvents were used as received from Sigma Aldrich unless otherwise specified. Doubly distilled deionized water was obtained from a Millipore Milli-Q water purification system (Millipore). 1-Tetradecyl-3-methylimidazolium bromide; $\left[\mathrm{C}_{14} \mathrm{mim}^{+}\right]\left[\mathrm{Br}^{-}\right]$was synthesized according to a procedure reported in the literature ${ }^{30}$ and dried in vacuum for at least $48 \mathrm{~h}$ at $333 \mathrm{~K}$ before use. Solutions were prepared with doubly distilled Millipore Milli-Q water.

\subsection{Methods.}

\subsubsection{Surface tension measurements (ST).}

ST measurements were carried out at two different experimental conditions; $\mathrm{pH} 7$ and $\mathrm{pH}$ 12, using a Krüss manual tensiometer K20 by the Du Noüy ring method. Prior to each experiment, the tensiometer was calibrated at $298 \mathrm{~K}$ with doubly distilled Millipore Milli-Q water. The temperature was controlled at $298 \pm 0.1 \mathrm{~K}$ using a thermostatic bath. All measurements were repeated at least 5 times. 


\subsubsection{Conductivity measurements.}

The samples were equilibrated at $298 \pm 0.1 \mathrm{~K}$ in a thermostatic bath, and then conductivity measurements were performed on a Consort C832 apparatus, which was calibrated with $\mathrm{KCl}$ solutions. The cmc was calculated as the intersection point of the two linear regimes in the conductivity-concentration graph. The degree of counter ion binding was calculated using the following equation $\beta=1-\alpha$, where $\alpha$ is the degree of ionization derived from the ratio of the slopes between the two linear fragments of the conductivity curves. All measurements were made at $\mathrm{pH} 7$ and were repeated 3 times. The small conductivity of water was always subtracted from the measured data.

\subsubsection{Steady-state fluorescent measurements.}

Steady-state fluorescence spectra were taken on a Jobin-Yvon Fluoromax-P photoncounting spectrofluorometer. The selected excitation wavelength $\left(\lambda_{\mathrm{ex}}\right)$ was $335 \mathrm{~nm}$ and the emission spectra were scanned from 350 to $500 \mathrm{~nm}$. Pyrene $(2.0 \mu \mathrm{M})$ and Ntetradecylpyridinium bromide $\left(\left[\mathrm{C}_{14} \mathrm{Py}^{+}\right]\left[\mathrm{Br}^{-}\right]\right)(0-0.25 \mathrm{mM})$ were used as florescence probe and quencher, respectively. An appropriate volume of pyrene solution in methanol was introduced into a volumetric flask, and the solution was purged with a stream of nitrogen. Intensities of first $\left(\mathrm{I}_{1}\right)$ and third $\left(\mathrm{I}_{3}\right)$ vibronic bands in the pyrene emission spectra located at 373 and $384 \mathrm{~nm}$, respectively, were used to obtain the cmc value from the surfactant concentration dependence of the $I_{1} / I_{3}$ ratio. All measurements were performed at $\mathrm{pH} 7$ and $\mathrm{pH} 12$ at $298 \mathrm{~K}$ and were repeated at least three times.

\subsubsection{Isothermal titration calorimetry.}

ITC measurements were executed using a MicroCal VP-ITC microcalorimeter at $\mathrm{pH} 7$ and $\mathrm{pH} 12.10 \mu \mathrm{L}$ volumes of $3.4 \mathrm{mM}\left[\mathrm{C}_{14} \mathrm{mim}^{+}\right]\left[\mathrm{Br}^{-}\right]$aqueous solution were injected from the computer-controlled microsyringe at an interval of $180 \mathrm{~s}$ into the cell (volume $=1.4569 \mathrm{~mL}$ ) containing $50 \mathrm{mM}$ of amino acid solutions, while stirring at $450 \mathrm{rpm}$. Triplicate measurements were taken for each of the experimental points. 


\subsubsection{NMR measurements.}

The $400 \mathrm{MHz}$ Bruker AC-NMR spectrometer was utilized to probe ${ }^{1} \mathrm{H}$ NMR shifts of the signals of $\left[\mathrm{C}_{14} \mathrm{mim}^{+}\right]\left[\mathrm{Br}^{-}\right]$surfactant upon addition of amino acids in deuterated water $\left(\mathrm{D}_{2} \mathrm{O}\right)$ relative to tetramethylsilane internal standard. The acquisition of spectra and its analysis were handled by MestReNova software. All experiments were performed at pH 7 and 12 at $298 \pm 0.1 \mathrm{~K}$.

\section{Results and Discussion}

\subsection{Characterization of the self-aggregation properties of $\left[\mathrm{C}_{14} \mathrm{mim}^{+}\right]\left[\mathrm{Br}^{-}\right]$.}

We have examined the effect of some AA such as L-Ala, L-Phe and L-Trp on the selfaggregation behavior of the surfactant $\left[\mathrm{C}_{14} \mathrm{mim}^{+}\right]\left[\mathrm{Br}^{-}\right]$in aqueous solution at $298 \mathrm{~K}$. In order to investigate the formation of micelles in water, the cmc of $\left[\mathrm{C}_{14} \mathrm{mim}^{+}\right]\left[\mathrm{Br}^{-}\right]$in presence of AAs were measured in aqueous solution at $\mathrm{pH} 7$ and $\mathrm{pH} 12$ by four techniques such as; surface tension, conductivity, steady-state fluorescence, and ITC techniques. Furthermore, thermodynamics and surface parameters were determined. The results will be discussed in the following paragraphs in detail.

\subsubsection{Determination of cmc values.}

\section{Surface tension measurements.}

Figure 2 shows the variation of the ST $(\gamma)$ as a function of the logarithm of $\left[\mathrm{C}_{14} \mathrm{mim}^{+}\right]\left[\mathrm{Br}^{-}\right]$ concentration in presence of $50 \mathrm{mM} \mathrm{AA}$ at $\mathrm{pH} 7$ and $\mathrm{pH} 12$; respectively. The experimental data at pH 7 and pH 12 are summarized in Supporting Information, in Table S1 and S2, respectively. As we can see in Figure 2, after the initial gradual diminution, a break point is observed which corresponds to the cmc. The cmc values obtained to $\left[\mathrm{C}_{14} \mathrm{mim}^{+}\right]\left[\mathrm{Br}^{-}\right]$in absence and in presence of AAs at both pHs are show in Table 1. 

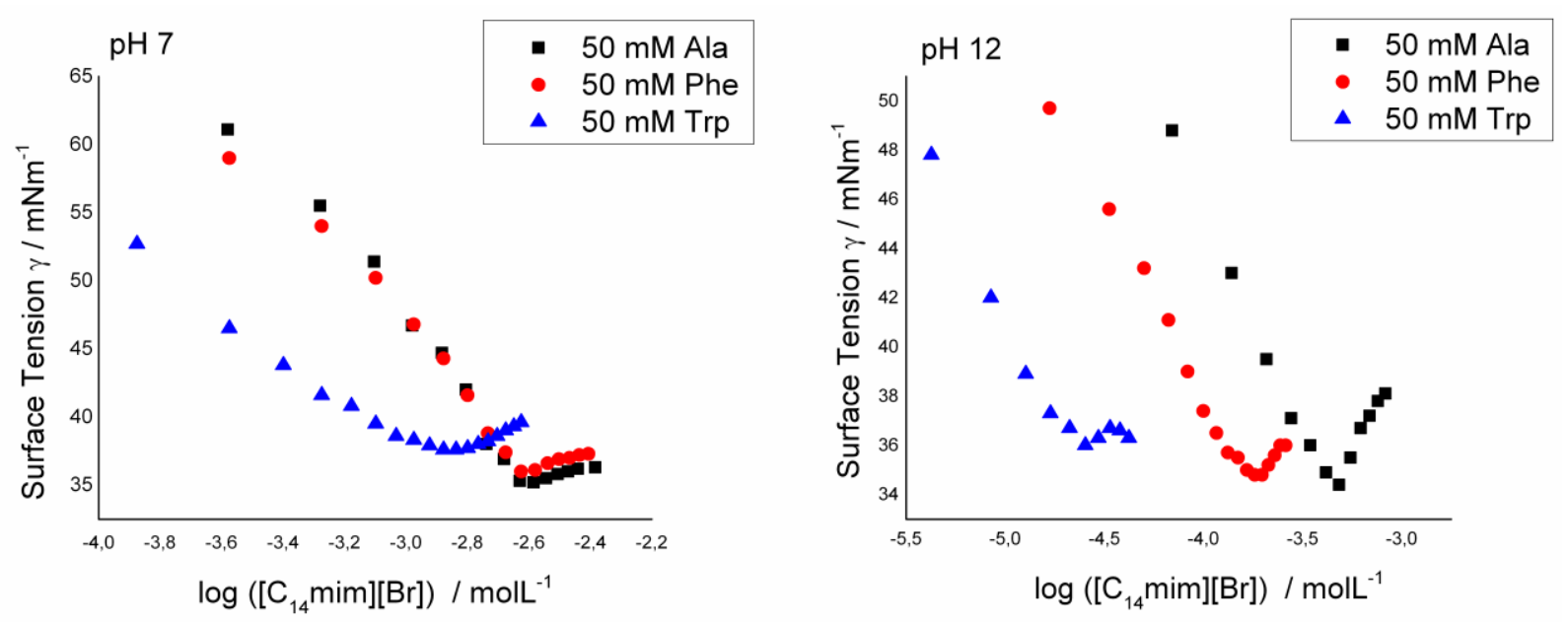

Figure 2. Surface tension $v s \log \mathrm{C}$ isotherms for $\left[\mathrm{C}_{14} \mathrm{mim}^{+}\right]\left[\mathrm{Br}^{-}\right]$aqueous solution in the presence of $50 \mathrm{mM} \mathrm{AAs}$, at $\mathrm{pH} 7$ and $\mathrm{pH} 12$.

\section{Conductivity measurements.}

Two readily distinguishable linear correlations appear when the specific conductivity $(\kappa)$ is plotted as a function of $\left[\mathrm{C}_{14} \mathrm{mim}^{+}\right]\left[\mathrm{Br}^{-}\right]$concentration in aqueous solution in presence of AAs at $\mathrm{pH} 7$ (see Figure 3). At low surfactant concentrations, the growth of $\kappa$ is attributed to the increase of the number of free $\left[\mathrm{C}_{14} \mathrm{mim}^{+}\right]$and $\left[\mathrm{Br}^{-}\right]$ions, whereas the break in the change of the slope arises from the onset of micelle formation. Above cmc, the binding of a fraction of the counterions to the micellar surface and the low mobility of micelles leads to a smaller slope for the concentration dependence of $\kappa .{ }^{31}$ The larger slope above cmc in the presence of L-Trp may indicate smaller extent of counterion association with micelle and/or smaller micelle size. The intersection of the two linear correlations, which corresponds to the cmc, appears at lower surfactant concentration in L-Trp solution than in the case of the other AAs. The parameters calculated from conductivity experiments are given in Table S3 in Supporting Information. The degree of counterion binding $(\beta)$ can be estimated from the ratio of the slopes ${ }^{32}$ and indicates the amount of anions on the surface of the micelles. Because of the high $\mathrm{Na}^{+}$and $\mathrm{OH}^{-}$concentrations, conductivity measurement does not provide information on the micellization at $\mathrm{pH} 12$. The $\mathrm{cmc}$ and $\beta$ values obtained for $\left[\mathrm{C}_{14} \mathrm{mim}^{+}\right][\mathrm{Br}-]$ in presence of AAs at $\mathrm{pH} 7$ are show in Table 1. 

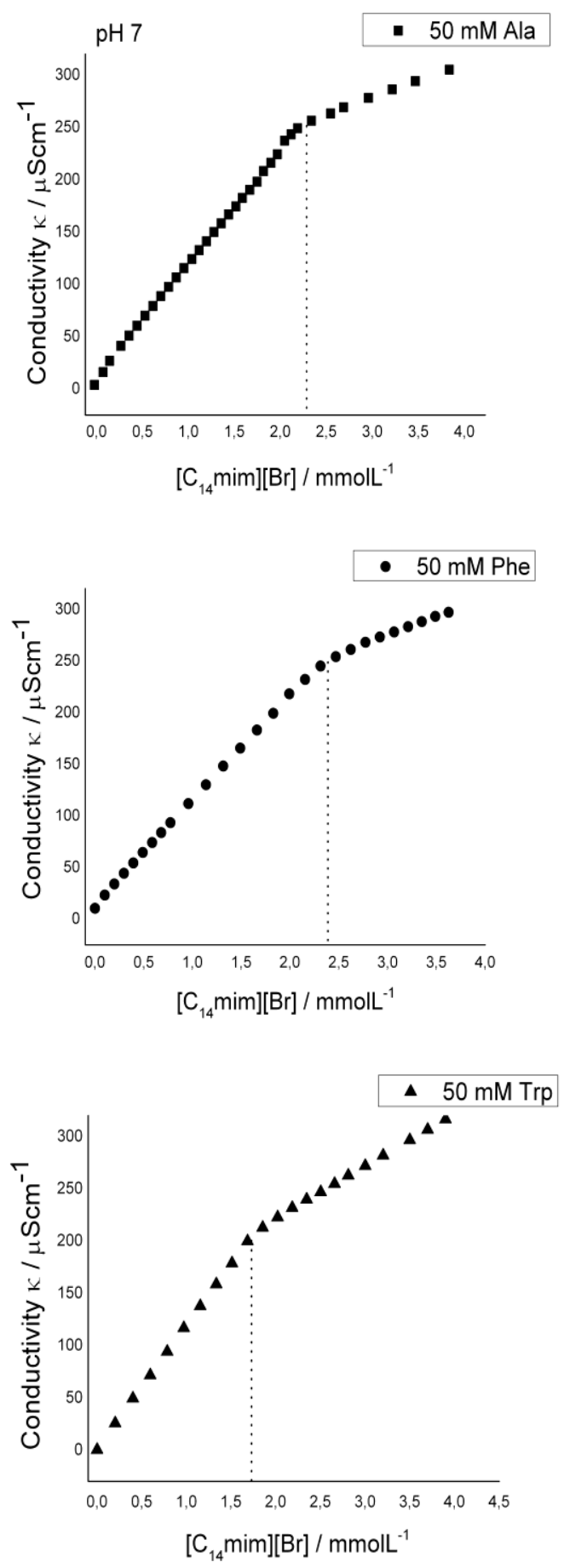

Figure 3. Specific conductance $v s$ concentration isotherms for $\left[\mathrm{C}_{14} \mathrm{mim}^{+}\right]\left[\mathrm{Br}^{-}\right]$aqueous solution at $\mathrm{pH} 7$, in presence of $50 \mathrm{mM}$ of AA. 


\section{Steady-state fluorescence measurements.}

The alteration of the steady-state fluorescence spectrum of pyrene probe was also used to determine the cmc values of $\left[\mathrm{C}_{14} \mathrm{mim}^{+}\right]\left[\mathrm{Br}^{-}\right]$in presence of each AA. The pyrene emission has characteristic five vibronic bands in the region from 370 to $425 \mathrm{~nm}$ (see Figure S1 in Supporting Information). When pyrene is dissolved in surfactant, the intensity of the first band decreases due to less polar microenvironment compared with water, while the third band is not sensitive to the surroundings of the excited molecule. Thus, the ratio of the intensities of the first to third bands $\left(\mathrm{I}_{1} / \mathrm{I}_{3}\right)$ is useful to probe the micropolarity. In addition, when the ratio $\left(\mathrm{I}_{1} / \mathrm{I}_{3}\right)$ is correlated with the surfactant concentration, break point corresponds to the cmc value.

The plots showing the variation of the $I_{1} / I_{3}$ ratio with the concentration of $\left[\mathrm{C}_{14} \mathrm{mim}^{+}\right]\left[\mathrm{Br}^{-}\right]$in aqueous solution and in presence of each $\mathrm{AA}$ at $\mathrm{pH} 7$ and $\mathrm{pH} 12$ are shown in Figure 4. The variations of the $\mathrm{I}_{1} / \mathrm{I}_{3}$ ratio calculated are presented in Table S4 and S5 in Supporting Information. The overlap between the emission of pyrene and L-Trp thwarted the determination of cmc by fluorescence method in the presence of this AA.
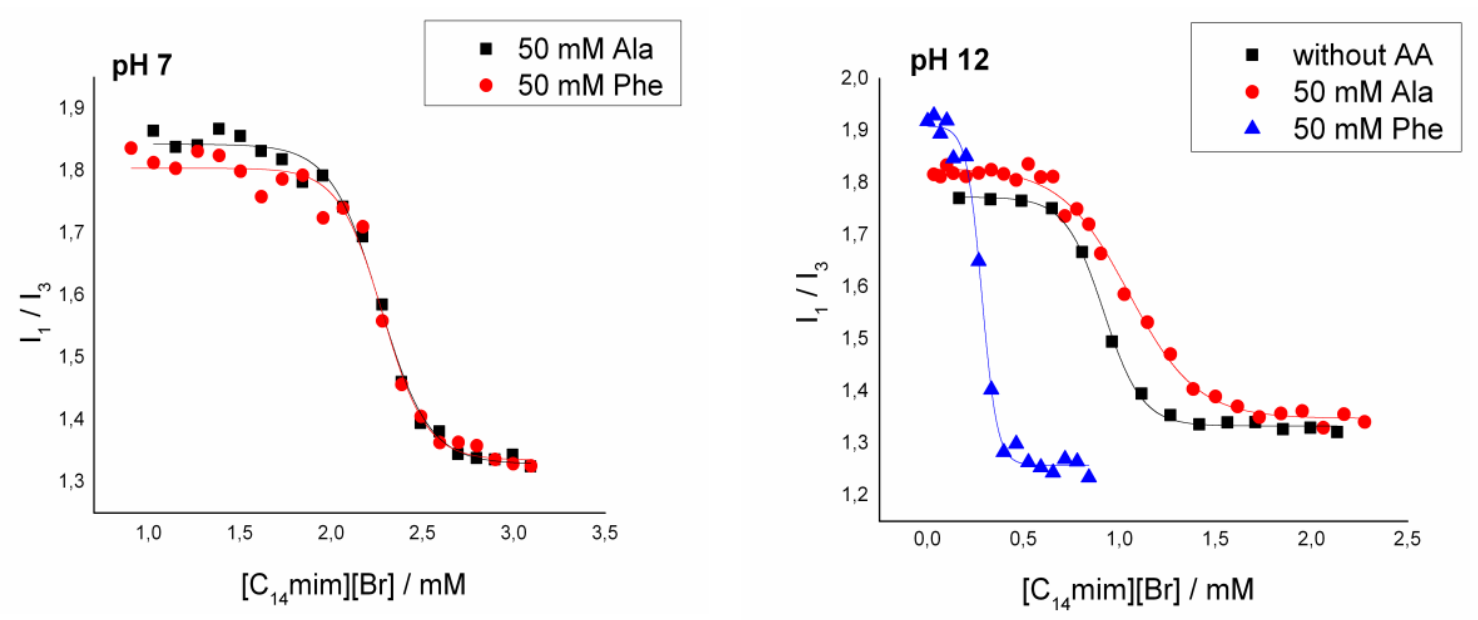

Figure 4. Variation of the $I_{1} / I_{3}$ ratio with the concentration of aqueous solution of $\left[\mathrm{C}_{14} \mathrm{mim}^{+}\right]\left[\mathrm{Br}^{-}\right]$; i) $\mathrm{pH} \mathrm{7}$ : in presence of $50 \mathrm{mM}$ of L-Ala and L-Phe, ii) $\mathrm{pH} \mathrm{12:} \mathrm{in} \mathrm{absence}$ and in presence of $50 \mathrm{mM}$ of L-Ala and L-Phe, at $25^{\circ} \mathrm{C}$.

\section{Isothermal titration calorimetry.}


Finally, ITC measurements were performed in order to determine the cmc values of $\left[\mathrm{C}_{14} \mathrm{mim}^{+}\right]\left[\mathrm{Br}^{-}\right]$and to obtain the thermodynamic parameters of micellization in presence of each $\mathrm{AA}$ at $\mathrm{pH} 7$ and $\mathrm{pH}$ 12. Figures 6 show the enthalpograms of dilution in presence of L-Ala, L-Phe and L-Trp at $\mathrm{pH} 7$, respectively. The results of analogous experiments at $\mathrm{pH}$ 12 are presented in Figures 7. These profiles can typically be described in terms of three different regions. At low concentrations of the surfactant a relatively large and constant enthalpy change $(\Delta \mathrm{H})$ is observed due to the complete dissociation of the micelles of the titrant solution. The second region is characterized by a sharp and decreasing endothermic effect indicating that the only a fraction of the injected micelles disintegrate. In the third concentration range no disaggregation occurs because micelles exit in the titrant solution. The enthalpy change of demicellization $\left(\Delta \mathrm{H}_{\text {demic }}\right)$ was determined as described by Blume and coworkers. ${ }^{33}$ The alteration of the dilution enthalpy $v s$ concentration of $\left[\mathrm{C}_{14 \mathrm{mim}^{+}}\right]\left[\mathrm{Br}^{-}\right]$ in the presence of each AA at $\mathrm{pH} 7$ and $\mathrm{pH} 12$ are shown in Table S6 and S7, respectively in Supporting Information.

The cmc values were obtained from the inflection points, as determined from the first derivative of the enthalpogram, as shown in Figure S4 in Supporting Information, for $\left[\mathrm{C}_{14} \mathrm{mim}^{+}\right]\left[\mathrm{Br}^{-}\right]$in aqueous solution in presence of L-Ala, L-Phe and L-Trp at $\mathrm{pH} 7$; respectively. Similarly, the cmc values at $\mathrm{pH} 12$ were obtained from the inflection points. Figures S5 in Supporting Information show the first order differential of the enthalpy

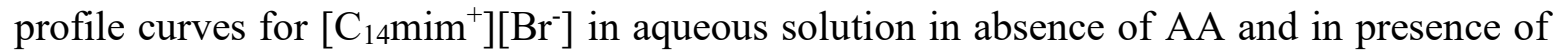
L-Ala, L-Phe and L-Trp at pH 12. 

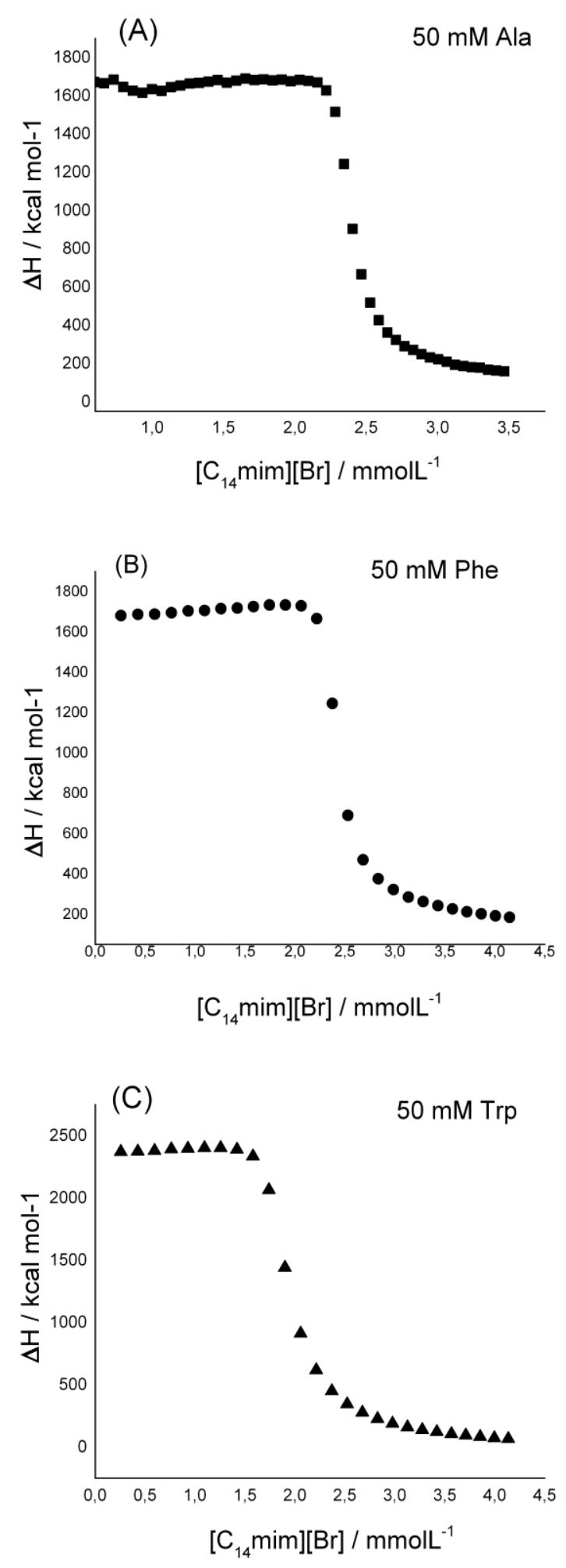

Figure 6. Raw titration data from ITC in $\mathrm{kcalmol}^{-1}$; each peak corresponds to a single injection of $\left[\mathrm{C}_{14} \mathrm{mim}^{+}\right]\left[\mathrm{Br}^{-}\right]$aqueous solution, in presence of each $\mathrm{AA}$, at $\mathrm{pH} 7$. 

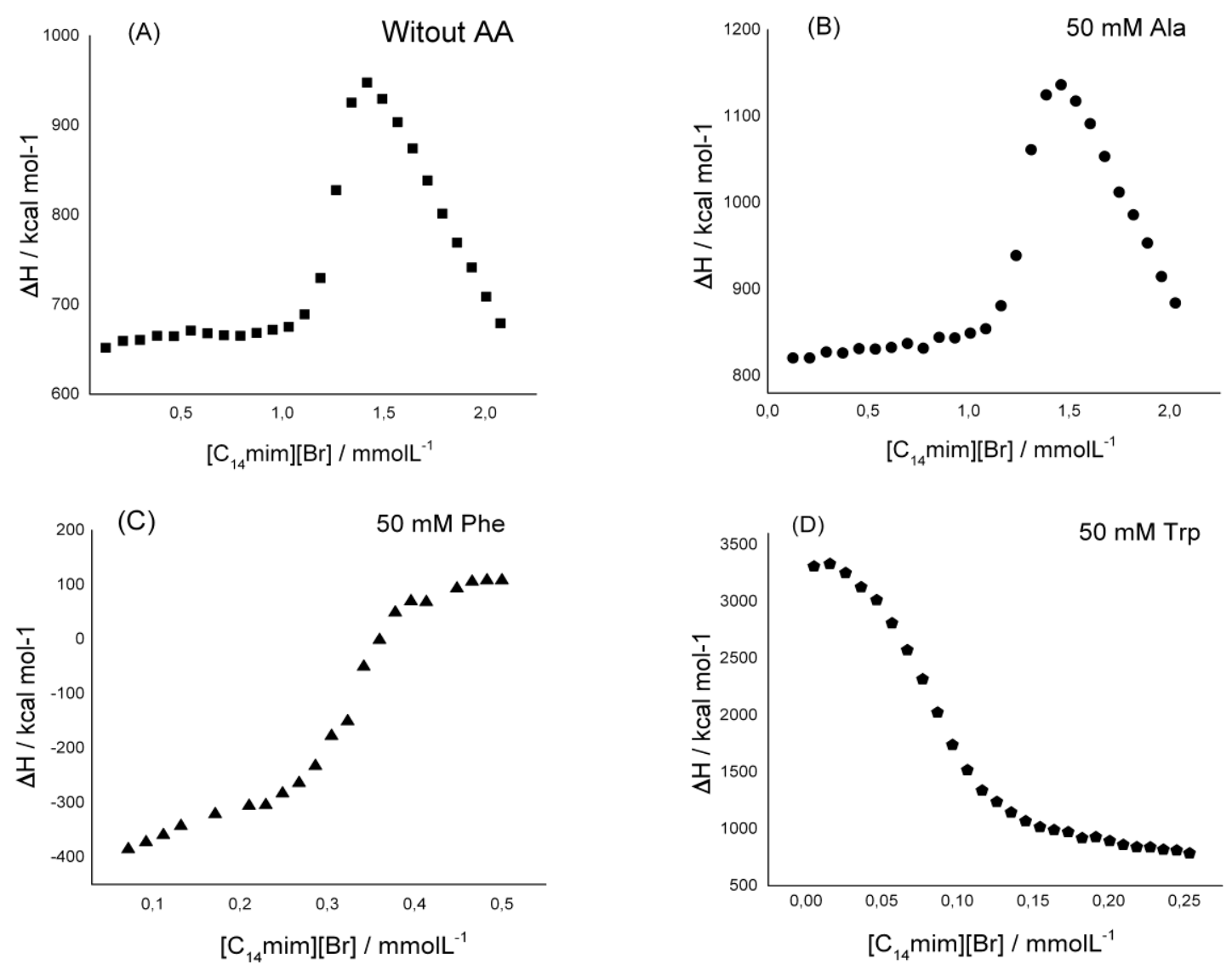

Figure 7. Raw titration data from ITC in $\mathrm{kcalmol}^{-1}$; each peak corresponds to a single injection of $\left[\mathrm{C}_{14} \mathrm{mim}^{+}\right]\left[\mathrm{Br}^{-}\right]$aqueous solution, in presence of each $\mathrm{AA}$, at $\mathrm{pH} 12$.

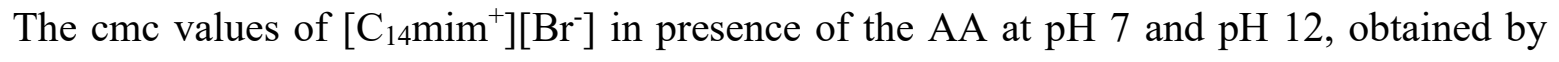
four independent methods are summarized in Table 1.

Table 1. Cmc of $\left[\mathrm{C}_{14} \mathrm{mim}^{+}\right]\left[\mathrm{Br}^{-}\right]$with different amino acids $(50 \mathrm{mM})$, at two pHs. Each measurement was made in triplicate. 


\begin{tabular}{|c|c|c|c|c|c|c|c|c|c|c|}
\hline \multirow[b]{2}{*}{$\begin{array}{c}\text { Amino } \\
\text { Acid }\end{array}$} & \multirow[b]{2}{*}{ pH } & \multicolumn{4}{|c|}{ Surface Tension } & \multicolumn{2}{|c|}{ Conductivity } & \multirow{2}{*}{$\begin{array}{c}\text { ITC } \\
\text { CMC / } \\
\text { mM }\end{array}$} & \multicolumn{2}{|c|}{ Fluoresce } \\
\hline & & $\begin{array}{c}\mathrm{CMC} / \\
\mathbf{m M}\end{array}$ & $\begin{array}{c}\prod_{\mathrm{cmc}} \\
\mathrm{mNm}^{-1}\end{array}$ & $\begin{array}{c}\Gamma_{\max } / \\
\left(10^{4}\right. \\
\left.\mathrm{mol} / \mathrm{m}^{2}\right)\end{array}$ & $\begin{array}{c}A_{\min } \\
/ \\
\mathbf{n m}^{2}\end{array}$ & $\begin{array}{c}\mathrm{CMC} / \\
\mathrm{mM}\end{array}$ & $\beta$ & & $\begin{array}{c}\mathrm{CMC} / \\
\mathbf{m M}\end{array}$ & $\mathbf{N}_{\text {agg }}$ \\
\hline - & 7 & $2.50^{34}$ & $33.8^{34}$ & 18 & 0.92 & $2.50^{34}$ & $0.76^{34}$ & $2.50^{34}$ & $2.50^{34}$ & $59^{34}$ \\
\hline L-Ala & 7 & $2.45 \pm 0.02$ & 34.7 & 15 & 1.09 & $2.21 \pm 0.04$ & 0.72 & $2.43 \pm 0.04$ & $2.26 \pm 0.01$ & 49 \\
\hline L-Phe & 7 & $2.36 \pm 0.02$ & 32.2 & 10.7 & 1.56 & $2.33 \pm 0.03$ & 0.65 & $2.47 \pm 0.07$ & $2.26 \pm 0.03$ & 57 \\
\hline L-Trp & 7 & $1.24 \pm 0.02$ & 31.1 & 0.66 & 8.6 & $1.76 \pm 0.02$ & 0.56 & $1.90 \pm 0.04$ & $* *$ & $* *$ \\
\hline- & 12 & $0.61 \pm 0.01$ & 35.7 & 4.10 & 26.2 & $* * *$ & $* * *$ & $1.34 \pm 0.02$ & $0.91 \pm 0.01$ & 63 \\
\hline L-Ala & 12 & $0.48 \pm 0.01$ & 32.4 & 7.44 & 2.40 & $* * *$ & $* * *$ & $1.31 \pm 0.02$ & $1.05 \pm 0.02$ & 58 \\
\hline L-Phe & 12 & $0.18 \pm 0.01$ & 34.4 & 2.19 & 7.57 & $* * *$ & $* * *$ & $0.322 \pm 0.003$ & $0.28 \pm 0.01$ & 55 \\
\hline L-Trp & 12 & $0.025 \pm 0.002$ & 35.6 & 1.92 & 8.64 & $* * *$ & $* * *$ & $0.075 \pm 0.002$ & $* *$ & $* *$ \\
\hline
\end{tabular}

** It was not possible to measure cmc by fluorescence technique due to L-Trp fluorescence

*** It was not possible to obtain information by conductivity techniques due to the high background conductivity at $\mathrm{pH} 12$.

As we can see in Table 1, the cmc values found to $\left[\mathrm{C}_{14} \mathrm{mim}^{+}\right]\left[\mathrm{Br}^{-}\right]$by different techniques (surface tension, conductivity, ITC and fluorescence) in general agree closely with each other. Nevertheless, ITC measured cmc values determined for $\left[\mathrm{C}_{14} \mathrm{mim}^{+}\right]\left[\mathrm{Br}^{-}\right]$at $\mathrm{pH} 12$ in absence of AA and in presence of L-Ala and L-Phe are higher, even values greater than double was observed in some cases. A similar behavior was observed by Sastry et al, when the critical aggregation concentration (cac) values determined by ST and ITC were compared. ${ }^{35}$ They reported important differences of cac values for some SAILs such as 1dodecyl-1-methylpiperidinium acetylsalicylate $\left[\mathrm{C}_{12} \mathrm{mpip}^{+}\right]\left[\mathrm{AcSa}^{-}\right]$and 1-dodecyl-1-methyl piperidinium chloride $\left[\mathrm{C}_{12} \mathrm{mpip}^{+}\right]\left[\mathrm{Cl}^{-}\right]$. ITC measurements provide different $\mathrm{cmc}$ because it reflects not only the aggregation but also the changes in the thermodynamic functions associated with microstructural changes during the aggregation process. ${ }^{36}$

On the other hand, the values of $\mathrm{cmc}$ in the Table 1 at $\mathrm{pH} 7$ and $\mathrm{pH} 12$ show differences among them. A larger effect on the cmc values was observed at $\mathrm{pH} 12$ in presence of each AA. These results are in accordance with the substantial electrostatic interactions between anionic forms of each AA (at $\mathrm{pH} 12$ ) with the cationic surfactant.

At $\mathrm{pH} 7$, slight interactions of the L-Ala with the surfactant $\left[\mathrm{C}_{14} \mathrm{mim}^{+}\right]\left[\mathrm{Br}^{-}\right]$were observed, compared with the effect found when L-Trp was the additive. These results could be explained due to the presence of a hydrophobic moiety on the L-Trp (indole group), that interacts strongly with the micellar interface of the $\left[\mathrm{C}_{14} \mathrm{mim}^{+}\right]\left[\mathrm{Br}^{-}\right]$, favoring micelle 
formation at a lower cmc value. Interestingly, in the case of $\mathrm{pH} 12$, even higher effect was observed in the presence of each AA. The decrease in the cmc value follows the tendency: absence AA > L-Ala > L-Phe > L-Trp. Two effects contribute to this trend: (i) hydrophobic interactions between the surfactant and the aromatic moiety of AA and (ii) the electrostatic attraction between $\left[\mathrm{C}_{14 \mathrm{mim}}{ }^{+}\right]$and the anionic form of AA.

\subsubsection{Determination of surface parameters}

On the other hand, other surface active parameters could be determined for a surfactant when the self-aggregation properties are determined by a ST technique. ${ }^{37}$ In this context, the area per adsorbed molecule at the air/water interface $\left(A_{\min }\right)$, the surface excess concentration $\left(\Gamma_{\max }\right)$, and the surface pressure $\left(\pi_{\mathrm{CMC}}\right)$ were calculated. The equations used to calculate the surface-active parameters mention above are given in Supporting Information (see equations S1, S2 and S3). The results are shown in Table 1.

Interestingly, the $A_{\min }$ and $\Gamma_{\max }$ values (see Table 1) in general, decrease in presence of $\mathrm{AAs}$, at $\mathrm{pH}$ 12. These results could be explain due to that, L-Trp induce a better compaction of the surfactant at the interface and due to the electrostatic interaction between the surfactant $\left[\mathrm{C}_{14} \mathrm{mim}^{+}\right][\mathrm{Br}-]$ and the AAs. ${ }^{38}$

In addition, the steady-state fluorescence of pyrene probe was utilized to determine the aggregation number $\left(N_{a g g}\right)$ of $\left[\mathrm{C}_{14} \mathrm{mim}^{+}\right]\left[\mathrm{Br}^{-}\right]$surfactant under different experimental conditions by static luminescence quenching method proposed originally by Turro and Yekta. ${ }^{39}$ The logarithm of the pyrene fluorescence intensity ratios at a specific wavelength $\left(\mathrm{I}_{0} / \mathrm{I}\right)$ in the absence and in the presence of quencher provides a linear correlation with the concentration of quencher and from the slope; $N_{\text {agg }}$ can be determined. See equation S4 in Supporting Information. ${ }^{38,39}$ As an example, Figure 5 shows the change in pyrene fluorescence emission spectra as a function of the concentration of the quencher for the aqueous solution of $\left[\mathrm{C}_{14} \mathrm{mim}^{+}\right]\left[\mathrm{Br}^{-}\right](25 \mathrm{mM})$, in the presence of L-Phe, at $\mathrm{pH} 12$.

Figures S2 to S3 in Supporting Information show the same behaviour at pH 7 and $\mathrm{pH} 12$ in absence of AA and in presence of L-Ala and L-Phe; respectively. 


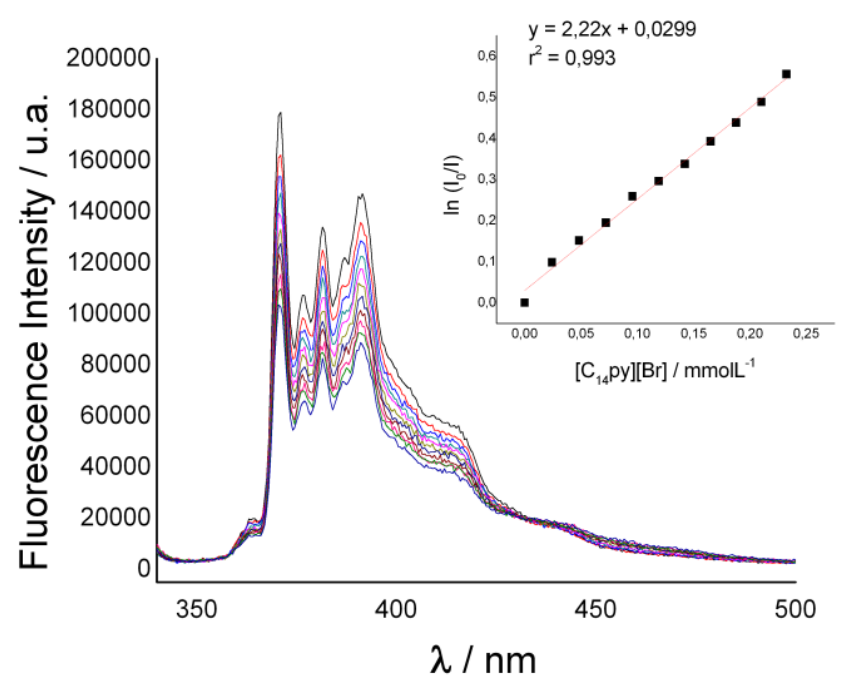

Figure 5. Plots of changes in the pyrene fluorescence spectra as a function of the concentration of quencher, N-tetradecylpyridinium bromide $\left(\left[\mathrm{C}_{14} \mathrm{py}^{+}\right]\left[\mathrm{Br}^{-}\right]\right)$, using $25 \mathrm{mM}$ $\left.\left[\mathrm{C}_{14} \mathrm{mim}^{+}\right]\left[\mathrm{Br}^{-}\right]\right)$in the presence of $50 \mathrm{mM} \mathrm{L-Phe} \mathrm{at} \mathrm{pH} \mathrm{12.} \mathrm{The} \mathrm{inset} \mathrm{shows} \mathrm{the} \mathrm{plot} \mathrm{of}$ $\ln \left(\mathrm{I}_{0} / \mathrm{I}\right)$ for pyrene $v s$ the concentration of the quencher, $\left[\mathrm{C}_{14} \mathrm{py}^{+}\right]\left[\mathrm{Br}^{-}\right]$, for the aqueous solution of $\left[\mathrm{C}_{14} \mathrm{mim}^{+}\right]\left[\mathrm{Br}^{-}\right](25 \mathrm{mM})$ in the presence of $50 \mathrm{mM}$ L-Phe at pH 12.

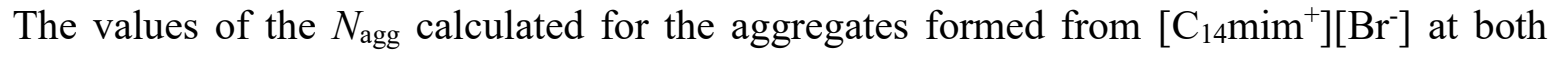
$\mathrm{pHs}$ in absence and in presence of AA are summarized in Table 1. As we can see, there is no tendency in neutral solution, but a clear trend appears at $\mathrm{pH} 12$. As the size of the AA increase, there is a decrease in the $N_{\text {agg. }}$ The decrease in the $N_{\text {agg }}$ value follows the trend: without AA > L-Ala > L-Phe.

\subsubsection{Determination of thermodynamics parameters.}

Additionally, thermodynamic parameters, namely, Gibbs free energy $\left(\Delta \mathrm{G}^{0}{ }_{\mathrm{mic}}\right)$, enthalpy $\left(\Delta \mathrm{H}^{0}{ }_{\text {mic }}\right)$, and entropy of micellization $\left(\Delta \mathrm{S}^{0}{ }_{\text {mic }}\right)$, have been obtained from ITC measurements. ITC is a label-free direct measurement of the heat evolved or absorbed during the aggregation process. Figure 6 at $\mathrm{pH} 7$ and figure 7 at $\mathrm{pH} 12$, shown the experimental data of the changes in heats of dilution as a function of the concentration was fitted by an independent site-binding model based on the sigmoidal Boltzman, procedure to calculate the $\Delta \mathrm{H}_{\text {demic. }}$ Since micellization is a reversible process, the enthalpy of demicellization is directly correlated to the enthalpy of micellization. 
The equations used to calculate the thermodynamic parameters mention above are given in Supporting Information, see equation S5 and S6. ${ }^{40,41}$ The summary of the thermodynamic parameters of micellization for $\left[\mathrm{C}_{14} \mathrm{mim}^{+}\right]\left[\mathrm{Br}^{-}\right]$in absence and in presence of each $\mathrm{AA}$, at pH 7 and $\mathrm{pH} 12$ are given in Table 2.

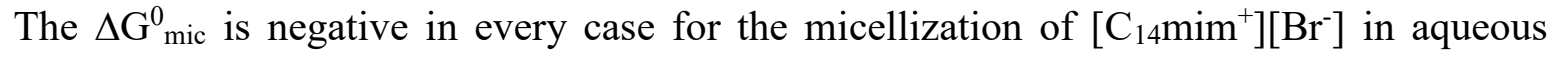
solution in the presence of the AA at two different pHs. This indicates the spontaneous nature of micellization of the surfactant. The negative value of $\Delta \mathrm{H}^{0}{ }_{\text {mic }}$ at $\mathrm{pH} 7$ and in the presence of L-Trp at pH 12 suggest the exothermic nature of micellization, while positive values in absence of AA, with L-ala and L-Phe at $\mathrm{pH} \mathrm{12,} \mathrm{indicate} \mathrm{that} \mathrm{the} \mathrm{micellization}$ process are endothermic. The values of $\Delta \mathrm{S}^{0}$ mic calculated are positive and always entropydriven micellization occurs.

A comparison of the thermodynamic parameters of micellization of the $\left[\mathrm{C}_{14} \mathrm{mim}^{+}\right]\left[\mathrm{Br}^{-}\right]$in the absence of AA and in the presence of L-Trp reveals that the free energy and enthalpy of micellization are more negative in presence of L-Trp than in absence of AA. This indicates that the L-Trp facilities the micellization process more favorably both at $\mathrm{pH} 7$ and at $\mathrm{pH} 12$.

Table 2. Thermodynamics parameters of micellization obtain from ITC for $\left[\mathrm{C}_{14} \mathrm{mim}\right][\mathrm{Br}]$ with amino acids.

\begin{tabular}{|c|c|c|c|c|}
\hline Amino acid & $\mathbf{p H}$ & $\begin{array}{l}\Delta \mathbf{G}^{0}{ }_{\text {mic }} / \\
\mathbf{k J ~ m o l}^{-1}\end{array}$ & $\begin{array}{l}\Delta \mathbf{H}^{0}{ }_{\text {mic }} / \\
\mathrm{kJ} \mathrm{mol}^{-1}\end{array}$ & $\begin{array}{l}\mathrm{T} \Delta \mathbf{S}^{0}{ }_{\text {mic }} / \\
\mathbf{k J} \mathrm{mol}^{-1}\end{array}$ \\
\hline - & 7 & -24.79 & -5.72 & 19.07 \\
\hline L-Ala & 7 & -24.89 & -5.82 & 19.07 \\
\hline L-Phe & 7 & -24.77 & -6.02 & 18.75 \\
\hline L-Trp & 7 & -25.48 & -9.40 & 16.08 \\
\hline - & 12 & -26.34 & 1.45 & 27.78 \\
\hline L-Ala & 12 & -26.4 & 1.61 & 28.01 \\
\hline L-Phe & 12 & -29.74 & 1.77 & 31.51 \\
\hline L-Trp & 12 & -33.65 & -7.46 & 26.19 \\
\hline
\end{tabular}

\subsubsection{Electrostatic interaction by NMR techniques.}


Finally, and in order to shed more light on the interaction between $\left[\mathrm{C}_{14} \mathrm{mim}^{+}\right]\left[\mathrm{Br}^{-}\right]$with the additives at $\mathrm{pH} 7$ and $\mathrm{pH} 12,{ }^{1} \mathrm{H}$ NMR technique was used. It provides information about average position of AA within the micellar aggregates. ${ }^{23}$

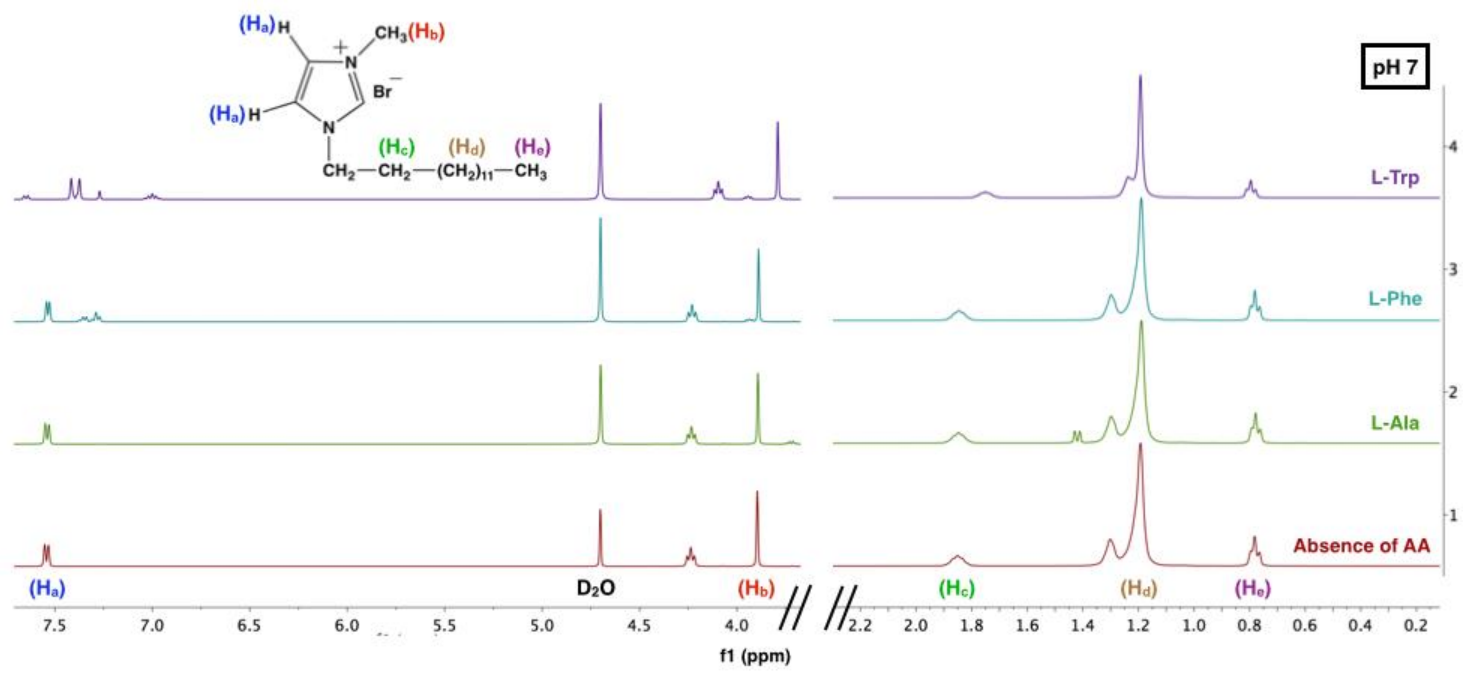

Figure 5. ${ }^{1} \mathrm{H}$ NMR spectrum of $\left[\mathrm{C}_{14} \mathrm{mim}^{+}\right]\left[\mathrm{Br}^{-}\right]$surfactant at $\mathrm{pH} 7$; in absence and in presence of each AA.

Figures 5 and 6 show the ${ }^{1} \mathrm{H}$ NMR spectrum of $\left[\mathrm{C}_{14} \mathrm{mim}^{+}\right]\left[\mathrm{Br}^{-}\right]$surfactant, in absence and in presence of AA, at $\mathrm{pH} 7$ and $\mathrm{pH} 12$ respectively. The concentration of $\left[\mathrm{C}_{14 \mathrm{mim}^{+}}\right]\left[\mathrm{Br}^{-}\right]$was 80 times higher than cmc $(200 \mathrm{mM})$. The Figures 5 and 6 show that the micellar core protons (called as $\mathrm{H}_{\mathrm{c}}, \mathrm{H}_{\mathrm{d}}$ and $\mathrm{H}_{\mathrm{e}}$ ) of $\left[\mathrm{C}_{14} \mathrm{mim}^{+}\right]\left[\mathrm{Br}^{-}\right]$surfactant in the absence of $\mathrm{AA}$ are highly shielded and therefore they are at low chemical shifts $(\delta)$ values. In addition, protons near the head group (these protons are called $\mathrm{H}_{\mathrm{a}}$ and $\mathrm{H}_{\mathrm{b}}$ ) resonate at higher $\delta$ values, due to deshielding effect caused by the positive charge of the imidazolium group. On the other hand, we can observe in Figure 5 that there is not a significant effect on the chemical shifts of the protons mention above after addition of L-Ala and L-Phe, suggesting a poor interaction between the surfactant and zwitterionic form of both AA. Nevertheless, when LTrp is added to $\left[\mathrm{C}_{14} \mathrm{mim}^{+}\right]\left[\mathrm{Br}^{-}\right]$solution, the signals of $\mathrm{H}_{\mathrm{a}}$ and $\mathrm{H}_{\mathrm{b}}$ protons are shifted upfield ( $\mathrm{H}_{\mathrm{a}}$ from 7.54 to $7.39 \mathrm{ppm}$ and $\mathrm{H}_{\mathrm{b}}$ from 3.90 to $3.79 \mathrm{ppm}$ ). These results could explain the trend of the cmc values found to $\left[\mathrm{C}_{14} \mathrm{mim}^{+}\right]\left[\mathrm{Br}^{-}\right]$in absence and presence of each AA. As mentioned above, small effect was observed in the cmc values when L-Ala and L-Phe were 
used as bio-additive, but a substantial decrease of cmc was observed in presence of L-Trp, where cmc decreased almost to half.

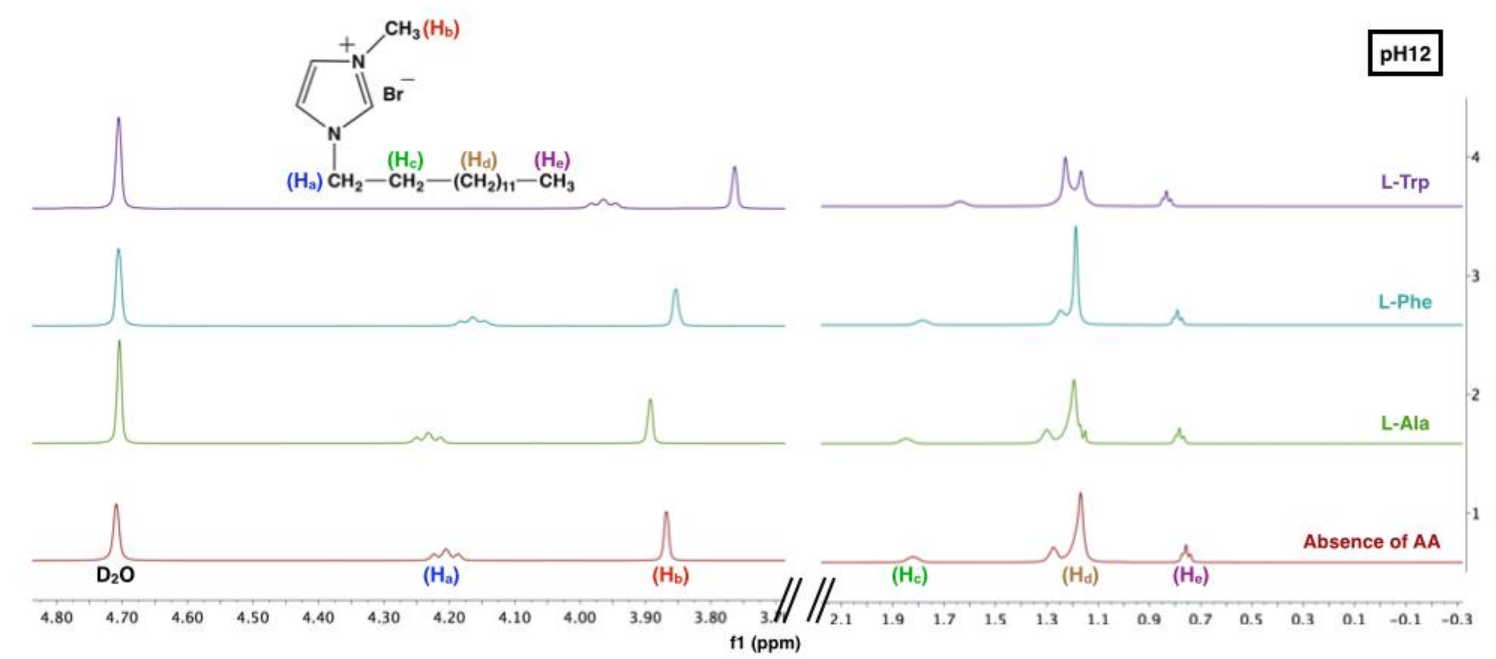

Figure 6. ${ }^{1} \mathrm{H}$ NMR spectrum of $\left[\mathrm{C}_{14} \mathrm{mim}^{+}\right]\left[\mathrm{Br}^{-}\right]$surfactant, in absence and in presence of each AA, at pH 12.

Figure 6 shows the effect after addition of each AA used in this study at pH 12 when all AAs are in the anionic form. There is not a significant effect on the chemical shifts of the core protons $\left(\mathrm{H}_{\mathrm{c}^{-}} \mathrm{H}_{\mathrm{e}}\right)$ after addition of L-Ala, L-Phe and L-Trp. Nevertheless, Figure 6 shows effect on chemical shifts of protons near the head group $\left(\mathrm{H}_{\mathrm{a}}\right.$ and $\left.\mathrm{H}_{\mathrm{b}}\right)$ after addition of L-Ala and L-Phe, which was not observed at $\mathrm{pH}$ 7. In addition, the effect on $\delta$ values of protons $\mathrm{H}_{\mathrm{a}}$ and $\mathrm{H}_{\mathrm{b}}$ is even higher when L-Trp is added to $\left[\mathrm{C}_{14} \mathrm{mim}^{+}\right]\left[\mathrm{Br}^{-}\right]$solution. $\left(\mathrm{H}_{\mathrm{a}}\right.$ from 4.20 to $3.96 \mathrm{ppm}$ and $\mathrm{H}_{\mathrm{b}}$ from 3.87 to $\left.3.76 \mathrm{ppm}\right)$.

This different behavior at $\mathrm{pH} 12$ can be explained by the electrostatic attraction between the cationic head group of $\left[\mathrm{C}_{14 \mathrm{mim}^{+}}\right]\left[\mathrm{Br}^{-}\right]$and the anionic form of AA. (Table S8 and S9 in Supporting Information, show all the chemical shifts $(\delta)$ values for $\mathrm{H}_{\mathrm{a}}-\mathrm{H}_{\mathrm{e}}$ at $\mathrm{pH} 7$ and 12; respectively).

Considering the NMR results mentioned above at $\mathrm{pH} 7$ and 12, we conclude that the anionic form interacts more than the zwitterionic form of each AA. Besides, the chemical shifts of $\mathrm{H}_{\mathrm{a}}$ and $\mathrm{H}_{\mathrm{b}}$ shown in Figures 5 and 6 also indicate that AA interacts mainly with the head group of $\left[\mathrm{C}_{14} \mathrm{mim}^{+}\right]\left[\mathrm{Br}^{-}\right]$. 


\section{Conclusion}

The micellization behaviour and thermodynamic properties of $\left[\mathrm{C}_{14} \mathrm{mim}^{+}\right]\left[\mathrm{Br}^{-}\right]$in aqueous solution at $\mathrm{pH} 7$ and 12 were determined in the absence and in the presence of AAs such as L-alanine, L-phenylalanine and L-tryptophan.

The critical micellar concentrations were determined by four independent methods, namely, surface tension, conductivity, steady state fluorescence, and isothermal titration calorimetry measurements. The cmc values, obtained by different techniques, closely agreed. However, ITC measurements at $\mathrm{pH} 12$ showed some cmc values higher compared with the other methods.

On the other hand, the greatest effect on the cmc values was observed at $\mathrm{pH} 12$ for all amino acids, there was a decrease in the cmc values at this experimental condition. Nevertheless, the greatest decrease in the cmc value was in the presence of L-Trp, at pH 12. These results could be explained due to the presence of a hydrophobic moiety on the L-Trp, that can interact strongly with the micellar interface of the $\left[\mathrm{C}_{14} \mathrm{mim}^{+}\right]\left[\mathrm{Br}^{-}\right]$, favoring micelle formation at a lower cme value.

Moreover, other surface parameters, such as; $A_{\min }, \Gamma_{\max }$ and $\pi_{\mathrm{CMC}}$, were determined from surface tension. Besides, steady state fluorescence techniques were used to determine the $N_{\text {agg }}$ of $\left[\mathrm{C}_{14} \mathrm{mim}^{+}\right]\left[\mathrm{Br}^{-}\right]$in presence of each AA. There is no tendency in neutral solution, but at $\mathrm{pH} 12$ there are a clear trend. The $N_{a g g}$ decrease from without AA $>$ L-Ala $>$ L-Phe, and could be attributed to the size of the additive.

In order to understand the interaction between $\left[\mathrm{C}_{14} \mathrm{mim}^{+}\right]\left[\mathrm{Br}^{-}\right]$with $\mathrm{AA}$ at $\mathrm{pH} 7$ and $\mathrm{pH} 12$, ${ }^{1} \mathrm{H}$ NMR technique was used. It was found that the anionic forms interact more than the zwitterionic forms of each additive. This result was explained by the electrostatic interaction between the cationic head group of $\left[\mathrm{C}_{14} \mathrm{mim}^{+}\right]\left[\mathrm{Br}^{-}\right]$and the anionic form of AA.

\section{Acknowledgements}

\section{References}

(1) Hallett, J. P.; Welton, T. Chem Rev 2011, 111, 3508.

(2) Welton, T. Coordin Chem Rev 2004, 248, 2459. 
(3) P. Wasserscheid, T. W. Ionic Liquids in Synthesis, 2003.

(4) Law, G.; Watson, P. R. Langmuir 2001, 17, 6138.

(5) Bhadani, A.; Singh, S. Langmuir 2009, 25, 11703.

(6) Zhao, Y.; Gao, S. J.; Wang, J. J.; Tang, J. M. J Phys Chem B 2008, 112, 2031.

(7) Yuan, J.; Bai, X. T.; Zhao, M. W.; Zheng, L. Q. Langmuir 2010, 26, 11726.

(8) Zhang, G. D.; Chen, X. A.; Xie, Y. Z.; Zhao, Y. R.; Qiu, H. Y. J Colloid Interf Sci 2007, 315, 601.

(9) Inoue, T.; Dong, B.; Zheng, L. Q. J Colloid Interf Sci 2007, 307, 578.

(10) Zhang, G. D.; Chen, X.; Zhao, Y. R.; Xie, Y. Z.; Qiu, H. Y. J Phys Chem B 2007, 111, 11708 .

(11) Zhao, Y. R.; Chen, X.; Jing, B.; Wang, X. D.; Ma, F. M. J Phys Chem B 2009, 113, 983 .

(12) Fang, D. W.; Zhang, F.; Jia, R.; Shan, W. J.; Xia, L. X.; Yang, J. Z. Rsc Adv 2017, 7, 11616 .

(13) Zorebski, M.; Zorebski, E.; Dzida, M.; Skowronek, J.; Jezak, S.; Goodrich, P.; Jacquemin, J. J Phys Chem B 2016, 120, 3569.

(14) Xue, L. J.; Gurung, E. S.; Tamas, G.; Koh, Y. P.; Shadeck, M.; Simon, S. L.; Maroncelli, M.; Quitevis, E. L. J Chem Eng Data 2016, 61, 1078.

(15) Blesic, M.; Marques, M. H.; Plechkova, N. V.; Seddon, K. R.; Rebelo, L. P. N.; Lopes, A. Green Chem 2007, 9, 481.

(16) Song, Z. H.; Xin, X.; Shen, J. L.; Zhang, H.; Wang, S. B.; Yang, Y. Z. Rsc Adv 2016, 6, 2966.

(17) Wei, Y.; Wang, F.; Zhang, Z. Q.; Ren, C. C.; Lin, Y. J Chem Eng Data 2014, $59,1120$.

(18) Singh, T.; Kumar, A. J Phys Chem B 2007, 111, 7843.

(19) Wang, H. Y.; Wang, J. J.; Zhang, S. B.; Xuan, X. P. J Phys Chem B 2008, $112,16682$.

(20) Kamboj, R.; Bharmoria, P.; Chauhan, V.; Singh, G.; Kumar, A.; Singh, S.; Kang, T. S. Phys Chem Chem Phys 2014, 16, 26040.

(21) Kamboj, R.; Bharmoria, P.; Chauhan, V.; Singh, S.; Kumar, A.; Mithu, V. S.; Kang, T. S. Langmuir 2014, 30, 15040.

(22) Zhao, Y. R.; Yue, X.; Wang, X. D.; Huang, D. D.; Chen, X. Colloid Surface A 2012, 412, 90 .

(23) Akram, M.; Bhat, I. A.; Kabir-ud-Din Colloid Surface A 2016, 493, 32.

(24) Sharma, K.; Chauhan, S. Colloid Surface A 2014, 453, 78.

(25) Naderi, O.; Sadeghi, R. J Chem Thermodyn 2016, 102, 68.

(26) Kumar, S.; Naqvi, A. Z.; Kabir-ud-Din Langmuir 2000, 16, 5252.

(27) Junquera, E.; Tardajos, G.; Aicart, E. Langmuir 1993, 9, 1213.

(28) Cassidy, M. A.; Warr, G. G. J Phys Chem-Us 1996, 100, 3237.

(29) L.Nitschke, L. H. Environmental aspects of Surfactants, in, 2002.

(30) Mukai, T.; Yoshio, M.; Kato, T.; Yoshizawa, M.; Ohno, H. Chem Commun

2005, 1333.

(31) Shanks, P. C.; Franses, E. I. J. Phys. Chem. 1992, 961794.

(32) Ao, M.; Kim, D. J. Chem. Eng. Data, 2013, 58, 1529.

(33) Sues, P. S.; Tuchtenhagen, W.; Blume, J. J. Phys. Chem., 1995, 99, 11742.

(34) Vanyur, R.; Biczok, L.; Miskolczy, Z. Colloid Surface A 2007, 299, 256. 
(35) Sastry, N. V.; Singh, D. K. Langmuir 2016, 32, 10000.

(36) Geng, F.; Liu, J.; Zheng, L. Q.; Yu, L.; Li, Z.; Li, G. Z.; Tung, C. H. J Chem Eng Data 2010, 55, 147.

(37) Adamson, A. W. Physical Chemistry of Surfaces, 1976.

(38) Yousuf, S.; Akram, M.; Kabir-ud-Din Colloid Surface A 2014, 463, 8.

(39) Turro, N. J.; Yekta, A. J Am Chem Soc 1978, 100, 5951.

(40) Muller, N. Langmuir 1993, 9, 96.

(41) Mehta, S. K.; Bhasin, K. K.; Chauhan, R.; Dham, S. Colloid Surface A 2005, $255,153$. 